\title{
Likelihood of $\mathrm{ACL}$ graft rupture: not meeting six clinical discharge criteria before return to sport is associated with a four times greater risk of rupture
}

\author{
Polyvios Kyritsis, ${ }^{1}$ Roald Bahr, ${ }^{1}, 2$ Philippe Landreau, ${ }^{1}$ Riadh Miladi, ${ }^{1}$ Erik Witvrouw ${ }^{1,3}$
}

${ }^{1}$ Aspetar Orthopaedic and Sports Medicine Hospital, Doha, Qatar

${ }^{2}$ Department of Sports Medicine, Oslo Sports Trauma Research Center, Norwegian School of Sports Science, Oslo, Norway

${ }^{3}$ Department of Physical Therapy and Motor Rehabilitation, Ghent University, Gent, Belgium

Correspondence to Dr Polyvios Kyritsis, Aspetar Orthopaedic and Sports Medicine Hospital, P O Box 29222, Doha, Qatar; polyvios.kyritsis@aspetar.com

Received 17 December 2015 Revised 26 April 2016 Accepted 27 April 2016 Published Online First 23 May 2016

\section{SLinked}

- http://dx.doi.org/10.1136/ bjsports-2016-096410

CrossMark

To cite: Kyritsis $P$, Bahr $R$, Landreau $\mathrm{P}$, et al. $\mathrm{Br} \mathrm{J}$ Sports Med 2016;50 946-951.

\section{ABSTRACT}

Background The decision as to whether or not an athlete is ready to return to sport (RTS) after ACL reconstruction is difficult as the commonly used RTS criteria have not been validated.

Purpose To evaluate whether a set of objective discharge criteria, including muscle strength and functional tests, are associated with risk of $\mathrm{ACL}$ graft rupture after RTS.

Materials and methods 158 male professional athletes who underwent an $\mathrm{ACL}$ reconstruction and returned to their previous professional level of sport were included. Before players returned to sport they underwent a battery of discharge tests (isokinetic strength testing at $60^{\circ}, 180^{\circ}$ and $300^{\circ} / \mathrm{s}$, a running $\mathrm{t}$ test, single hop, triple hop and triple crossover hop tests). Athletes were monitored for $\mathrm{ACL}$ re-ruptures once they returned to sport (median follow-up 646 days, range 1-2060).

Results of the 158 athletes, 26 (16.5\%) sustained an ACL graft rupture an average of 105 days after RTS. Two factors were associated with increased risk of $\mathrm{ACL}$ graft rupture: (1) not meeting all six of the discharge criteria before returning to team training (HR $4.1,95 \% \mathrm{Cl} 1.9$ to $9.2, p \leq 0.001$ ); and (2) decreased hamstring to quadriceps ratio of the involved leg at $60 \%$ (HR 10.6 per $10 \%$ difference, $95 \% \mathrm{Cl} 10.2$ to $11, \mathrm{p}=0.005$ ). Conclusions Athletes who did not meet the discharge criteria before returning to professional sport had a four times greater risk of sustaining an $\mathrm{ACL}$ graft rupture compared with those who met all six RTS criteria. In addition, hamstring to quadriceps strength ratio deficits were associated with an increased risk of an ACL graft rupture.

\section{INTRODUCTION}

After ACL reconstruction (ACLR) the typical goal is to return to sport (RTS) as quickly as possible, preferably performing at the same level as preinjury yet protected from re-rupture. To increase the chances of successful and safe RTS, specific criteria have been developed.

Many RTS criteria have been suggested, some based on the time from ACLR as the only criterion for RTS, ${ }^{1}$ others advocating combining time with subjective and objective criteria. ${ }^{2}$ The most commonly described tests are isokinetic strength tests, functional tests, clinical assessment and related subjective questionnaires. ${ }^{3}{ }^{4}$ Ardern et $a l^{5}$ reported that, after an ACLR, $81 \%$ of patients return to any kind of sport, $65 \%$ return to their pre-injury level of sports participation and only $55 \%$ return to competitive sports. Also, after RTS the risk of re-injury (graft rupture) ranges from $6 \%$ to $25 \%{ }^{6-13}$ whereas the risk of contralateral ACL injury ranges from $2 \%$ to $20.5 \% .^{13}$

Given the high incidence of re-ruptures of reconstructed ACLs, it is striking that among the studies examining potential risk factors for ACL re-injury, the main focus has been on non-modifiable factors like gender, age, activity level and anatomical characteristics. $^{714-21}$ In the only prospective study that addressed neuromuscular control and coordination, poor neuromuscular control was a risk factor for ACL graft rupture. ${ }^{14}$ Among 281 cases of ACLR, younger athletes had a higher chance of graft rupture than older athletes. ${ }^{15}$ A 10 -year difference in age was associated with a 2.6 times greater chance of ACL graft rupture. Among 1820 patients after primary ACLR, younger athletes had a higher activity level and a higher incidence of ACL re-injury. ${ }^{16}$ There was no gender difference in the rate of ACL graft ruptures. ${ }^{16}$ Compliance with rehabilitation programmes is substantially lower among younger athletes, which might also contribute to the higher ACL re-injury risk. ${ }^{7}$ Based on data from the Swedish National Knee Ligament Register, the combination of being young and playing football is a substantial risk factor for revision surgery. ${ }^{13} 17$

Quadriceps and hamstring strength contribute to a successful RTS. $^{18}$ However, it is unknown whether strength is a risk factor for an ACL graft rupture. In addition, other factors like poor knee alignment or poor neuromuscular control are often described as predisposing factors for ACL re-injuries, ${ }^{14} 16171920$ but only one study has reported data. In a study of 56 athletes by Paterno et al, transverse plane net moment impulse at the hip, dynamic frontal plane knee range of motion, side to side differences in sagittal plane, knee moment at initial contact and deficits in postural stability were associated with a three times greater risk of ACL graft rupture. ${ }^{14}$

The purpose of this study is to evaluate whether strength or functional tests, which are frequently used as RTS criteria, are risk factors for an ACL graft rupture in a group of male professional athletes.

\section{MATERIALS AND METHODS}

Approval was obtained from the Ethics Committee of the Anti-Doping Lab Qatar Institutional Review Board (IRB application number EX2013000006) and waiver of informed consent was received.

\section{Study design and participants}

In this study we included only male professional athletes registered with sports clubs in Qatar. 
All athletes were treated at Aspetar Orthopedic and Sports Medicine Hospital (Aspetar) with primary ACLR between 1 January 2008 and 21 September 2015. All players returned to normal team training, which is how we define RTS. International athletes and athletes who could not be followed up because they left the country were excluded. Of the 377 athletes identified as having been treated for an ACL injury during this period, 158 met our inclusion criteria (figure 1).

Aspetar employs medical staff (clinicians, physiotherapists, nurses) in the National Sports Medicine Program (NSMP), which provides medical and sports science services to all sport clubs in Qatar. As part of this programme, injured athletes are obliged to visit Aspetar for any injury. Consequently, all injuries are recorded in their hospital medical record. We were therefore able to capture all ACL graft ruptures occurring after RTS during the period from 1 January 2008 to 21 September 2015. By the end of this follow-up period all athletes included in this study had RTS for at least 6 months after completion of their rehabilitation, unless a graft rupture occurred, in which case this was the endpoint of follow-up. The average follow-up for athletes who suffered an ACL graft rupture after RTS was 105 days (range 1-874 days), whereas for those who had no graft rupture the average follow up was 731 days (range 182-2060 days).

Five surgeons were involved using two different surgical techniques: hamstring or bone-patellar tendon-bone (BPTB) grafts. Both techniques were standardised and a femoral tunnel via an anteromedial portal was used for all ACLRs.

Immediately after surgery, athletes who had only ACLR were advised to weight bear as tolerated and no brace was used. If, in addition, a meniscus repair was also done, a brace limiting knee range of motion from $0^{\circ}$ to $90^{\circ}$ was used for 4 weeks and the athletes were advised to weight bear as tolerated.

All athletes completed a rehabilitation programme at Aspetar, supervised by a specialised team of sports physiotherapists who only treat ACL-injured patients.

Rehabilitation was divided into three phases: (1) early; (2) intermediate; and (3) advanced. In the early phase the focus was on controlling swelling, restoration of range of motion and activation of the quadriceps and hamstring muscles. In the intermediate phase the focus was on optimisation of muscle strength, proprioception and neuromuscular control. Towards the end of this phase a running progression programme also took place. Finally, in the advanced phase, rehabilitation was sports-specific

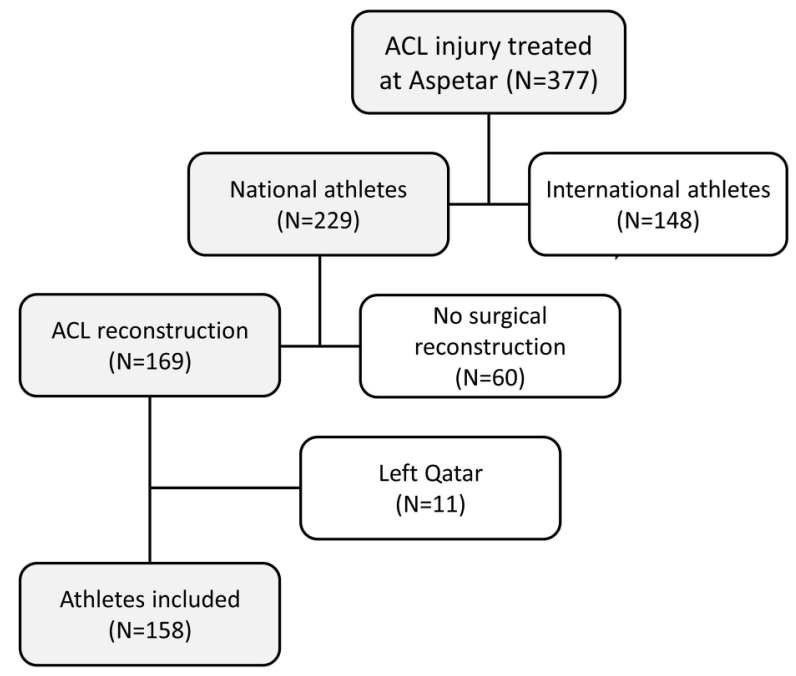

Figure 1 Flow chart of patient inclusion. with athletes starting to perform various sports- and positionspecific drills. At the end of this phase an assessment was conducted before allowing participation in normal team training. ${ }^{21}$ Our RTS criteria were criteria-based, not time-based.

Athletes who met all six discharge criteria (table 1) and were discharged clinically by their treating orthopaedic surgeons were recorded as 'fully discharged' for the purpose of this study. Athletes who did not meet the discharge criteria during the assessment, but who decided to RTS despite this, were classified as 'not fully discharged'.

\section{Data collection}

Strength

Concentric isokinetic tests were performed on both the involved and uninvolved quadriceps and hamstrings. Athletes were asked to perform five repetitions of knee extension and flexion for each leg at $60 \%$ and $180 \%$, and 20 repetitions at $300 \%$ s. A Biodex dynamometer (System 4, Biodex Medical Systems, Shirley, New York, USA) was used and peak torque, per cent of peak torque to body weight, work fatigue, average power and hamstrings to quadriceps peak torque ratio were recorded.

\section{Agility}

A running $t$ test was performed, which evaluates agility during running with changes of direction. Athletes were asked to run forward for $10 \mathrm{~m}$, then change to side-steps to the right for $5 \mathrm{~m}$, then $10 \mathrm{~m}$ of side-steps to the left, followed by $5 \mathrm{~m}$ of sidesteps to the right, ending with $10 \mathrm{~m}$ of backwards running (figure 2). ${ }^{22} 23$ Three repetitions were performed at maximum speed and the average time for the three repetitions was calculated.

\section{Hop performance}

Single and triple hop tests for distance were used. ${ }^{24-26}$ These tests measure the distance that an individual can cover while jumping on one leg. Athletes were instructed to perform a hop for a distance with each leg three times and the distance was recorded only if the landing was successful, without losing balance. The same procedure was followed for triple hop for distance test where athletes had to perform three continuous hops. Finally, the crossover hop test was performed. This test is a modified triple hop test during which athletes had to cross a line while performing the three hops. The results were recorded and the limb symmetry index was calculated as the hop distance of the involved leg divided by the hop distance of the uninvolved leg multiplied by 100 .

\section{Demographic and surgical information}

We recorded age at time of injury, weight and height, type of sport participation, duration of rehabilitation, date of surgery,

Table 1 Discharge tests and criteria used during the study period

\begin{tabular}{ll}
\hline Six-part return to sport tests & $\begin{array}{l}\text { Discharge permitted when each } \\
\text { of these criteria was met }\end{array}$ \\
\hline Isokinetic test at 60,180 and $300 \% \mathrm{~s}$ & $\begin{array}{l}\text { Quadriceps deficit }<10 \% \text { at } 60 \% \\
\text { Limb symmetry index }>90 \%\end{array}$ \\
Single hop & Limb symmetry index $>90 \%$ \\
Triple hop & Limb symmetry index $>90 \%$ \\
Triple crossover hop & Fully completed \\
On-field sports-specific rehabilitation & $<11 \mathrm{~s}$ \\
Running t test & L
\end{tabular}

Criteria were set according to the literature at the start of the study. 


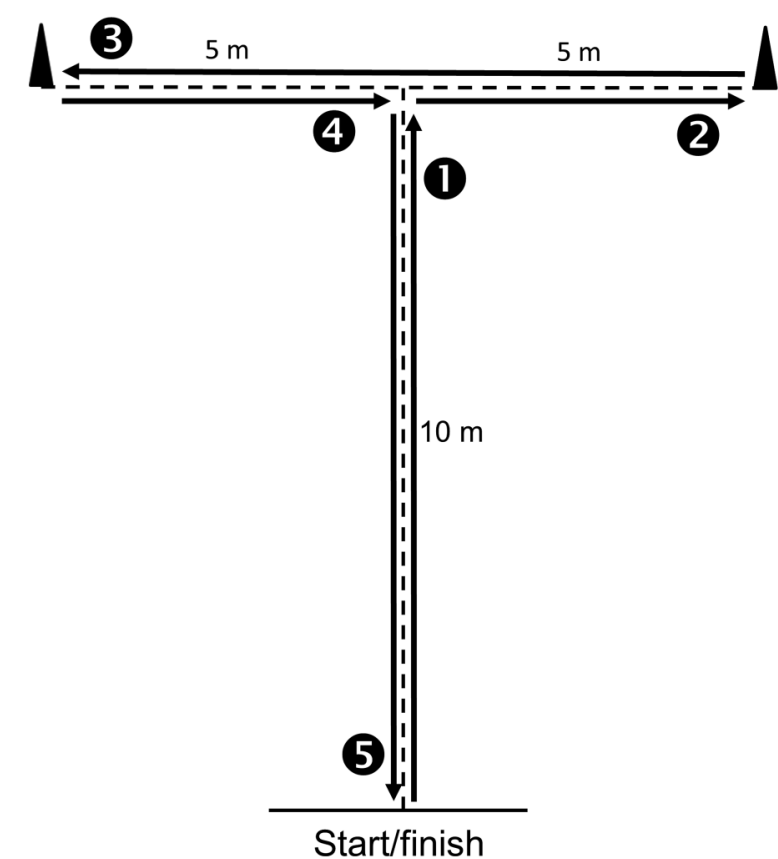

Figure 2 Agility running t test.

discharge date, graft type used, secondary injuries at the time of primary ACL injury (eg, cartilage lesions, meniscal tears, medial collateral ligament injuries) and whether or not the athletes met the discharge criteria.

\section{Statistical analysis}

All data were imported into SPSS V.21 for statistical analyses. All continuous variables were tested for normality and presented as the mean with SD. Between-group differences (ACL graft rupture vs no ACL graft rupture) were examined using an independent samples t test. To control the false discovery rate (FDR) arising from multiple comparisons, we used the BenjaminiHochberg procedure ${ }^{27}$ with $\mathrm{FDR}=0.25$ and computed adjusted $\mathrm{p}$ values. Any value of $<0.25$ was considered significant. For categorical variables, the association with ACL graft rupture was examined using a $\chi^{2}$ test. Any athlete characteristic or isokinetic parameter with a $\mathrm{p}$ value $<0.05$ was included in a backward stepwise Cox regression model to ascertain the effect of the variable on the likelihood that athletes had an ACL graft rupture. HRs with 95\% CIs were reported. A p value of $<0.05$ was considered statistically significant for the Cox regression.

\section{RESULTS}

Athletes $(\mathrm{N}=158)$ returned to their previous competitive level a mean of 229 days after surgery (range 116-513 days). Of these, $26(16.5 \%$ of 158$)$ sustained an ACL graft rupture and 11 (7.0\% of 158 ) sustained a contralateral rupture of their native ACL. Of the athletes who sustained an ACL graft rupture during the follow-up period, 17 (65.4\% of 26$)$ were re-injured within the first 6 months after RTS. The median time from RTS until ACL graft rupture was 105 days. Of the 158 athletes, 141 $(89 \%)$ were followed up for at least 6 months and $112(71 \%)$ for at least 12 months. Figure 3 depicts the cumulative prevalence of ACL graft ruptures.

Table 2 shows the anthropometric, injury and sport characteristics of the athletes. No significant differences were observed between the injured and non-injured groups. In both groups, football was the most frequently played sport, followed by

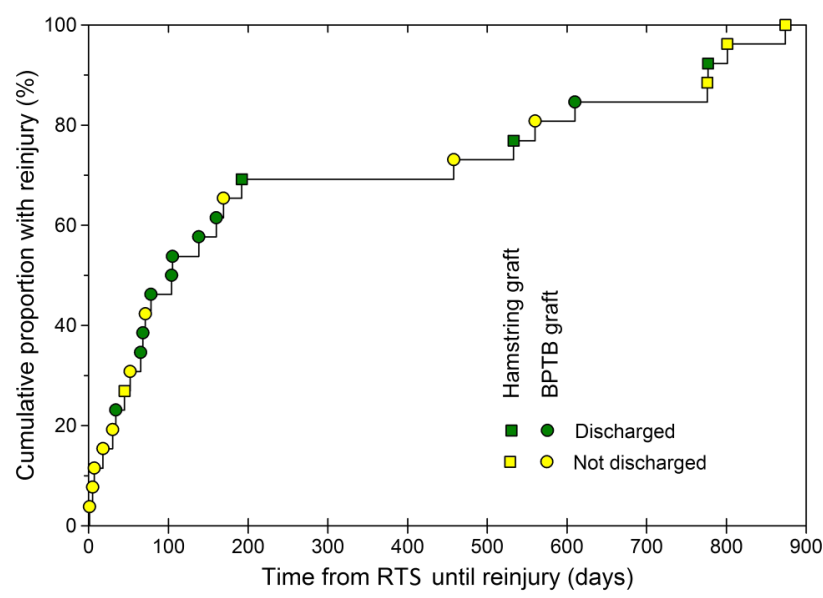

Figure 3 Cumulative prevalence of $A C L$ re-injuries $(n=26)$. Grey symbols denote players who were fully discharged, black symbols those not fully discharged. BPTB, bone-patellar tendon-bone; RTS, return to sport.

handball. Table 2 also shows the rehabilitation duration, secondary injuries and graft type of these two groups. Nineteen (73.1\%) of the 26 athletes who had an ACL graft rupture had a hamstring graft and seven (26.9\%) had a BPTB graft. Of all athletes who received a hamstring graft $(n=108), 17.6 \%$ suffered a re-rupture compared with $14.0 \%$ of all athletes who received a BPTB graft $(n=50)$.

Of the 158 athletes included, 116 (73\%) were fully discharged and 42 (27\%) were not. Among those fully discharged, $12(10.3 \%$ of 116$)$ suffered an ACL graft rupture compared with $14(33.3 \%$ of 42$)$ of those who were not fully discharged $(\mathrm{p}<0.001)$.

Table 3 shows the comparison of isokinetic and functional tests between the groups. Between-group differences were found in the per cent of peak torque to body weight of the involved hamstrings at $60 \%$, the hamstring to quadriceps ratio of the involved leg at $60 \%$, the average power of the involved hamstrings at 60,180 and $300 \%$ and the per cent of peak torque to

Table 2 Subject characteristics

\begin{tabular}{|c|c|c|c|}
\hline & $\begin{array}{l}\text { No } A C L \text { graft } \\
\text { rupture }(n=132)\end{array}$ & $\begin{array}{l}A C L \text { graft rupture } \\
(n=26)\end{array}$ & p Value \\
\hline Age (years) & $21(4)$ & $22(5)$ & 0.46 \\
\hline Weight $(\mathrm{kg})$ & $73.5(12)$ & $72.6(13.5)$ & 0.72 \\
\hline Height $(\mathrm{cm})$ & $176.3(7.7)$ & $177.5(6)$ & 0.46 \\
\hline $\begin{array}{l}\text { Rehabilitation } \\
\text { duration (days) }\end{array}$ & $247(68)$ & $221(63)$ & 0.07 \\
\hline Graft type & & & 0.57 \\
\hline Hamstring & $89(67.0 \%)$ & $19(73 \%)$ & \\
\hline ВРТВ & $43(33.0 \%)$ & $7(27 \%)$ & \\
\hline Secondary injuries & & & 0.08 \\
\hline Yes & $60(45 \%)$ & $7(27 \%)$ & \\
\hline No & $72(55 \%)$ & $19(73 \%)$ & \\
\hline Sport & & & 0.62 \\
\hline Football & $86(65.2 \%)$ & $19(73.1 \%)$ & \\
\hline Handball & $19(14.4 \%)$ & $2(7.7 \%)$ & \\
\hline Other & $27(20.5 \%)$ & $5(19.2 \%)$ & \\
\hline
\end{tabular}


Table 3 Isokinetic and functional test results

\begin{tabular}{|c|c|c|c|c|}
\hline \multirow[b]{2}{*}{ Variables } & \multirow{2}{*}{$\begin{array}{l}\text { No } A C L \text { graft } \\
\text { rupture }(n=132)\end{array}$} & \multirow{2}{*}{$\begin{array}{l}\text { ACL graft } \\
\text { rupture }(n=26)\end{array}$} & \multicolumn{2}{|l|}{$p$ Value } \\
\hline & & & Unadjusted & Benjamini-Hochberg \\
\hline \multicolumn{5}{|c|}{ Peak torque to body weight at $60 \% \mathrm{~s}(\%)$} \\
\hline Uninvolved quadriceps & $331(62)$ & $339(73)$ & 0.55 & 0.79 \\
\hline Involved quadriceps & $303(55)$ & $309(74)$ & 0.65 & 0.76 \\
\hline Uninvolved hamstrings & $180(28)$ & $174(30)$ & 0.30 & 0.45 \\
\hline Involved hamstrings & $172(31)$ & $159(33)$ & 0.05 & 0.07 \\
\hline \multicolumn{5}{|c|}{ Bilateral difference at $60 \% \mathrm{~s}(\%)$} \\
\hline Quadriceps & $-8(13)$ & $-9(14)$ & 0.88 & 0.88 \\
\hline Hamstrings & $-4(13)$ & $-8(14)$ & 0.16 & 0.48 \\
\hline \multicolumn{5}{|c|}{ Hamstring to quadriceps ratio at $60 \% \mathrm{~s}(\%)$} \\
\hline Involved leg & $58(10)$ & $53(11)$ & 0.04 & 0.12 \\
\hline Uninvolved leg & $55(8)$ & $52(8)$ & 0.15 & 0.23 \\
\hline \multicolumn{5}{|l|}{ Average power at $60^{\circ} / \mathrm{s}(\mathrm{W})$} \\
\hline Uninvolved quadriceps & $163(35)$ & $160(38)$ & 0.67 & 0.79 \\
\hline Involved quadriceps & $149(32)$ & $146(37)$ & 0.65 & 0.76 \\
\hline Uninvolved hamstrings & 97 (19) & $93(18)$ & 0.31 & 0.45 \\
\hline Involved hamstrings & $91(19)$ & $79(21)$ & 0.006 & 0.04 \\
\hline \multicolumn{5}{|c|}{ Peak torque to body weight at $180 \% \mathrm{~s}(\%)$} \\
\hline Uninvolved quadriceps & $238(35)$ & $235(38)$ & 0.69 & 0.79 \\
\hline Involved quadriceps & $217(36)$ & $207(41)$ & 0.23 & 0.51 \\
\hline Uninvolved hamstrings & $145(24)$ & $137(24)$ & 0.13 & 0.45 \\
\hline Involved hamstrings & $140(26)$ & $129(27)$ & 0.07 & 0.08 \\
\hline \multicolumn{5}{|c|}{ Bilateral difference at $180^{\circ} / \mathrm{s}(\%)$} \\
\hline Quadriceps & $-9(10)$ & $-12(12)$ & 0.21 & 0.48 \\
\hline Hamstrings & $-3(13)$ & $-5(15)$ & 0.54 & 0.67 \\
\hline \multicolumn{5}{|c|}{ Hamstring to quadriceps ratio at $180^{\circ} / \mathrm{s}(\%)$} \\
\hline Involved leg & $65(10)$ & $63(13)$ & 0.51 & 0.75 \\
\hline Uninvolved leg & $61(9)$ & $58(7)$ & 0.14 & 0.23 \\
\hline \multicolumn{5}{|c|}{ Average power at $180^{\circ} / \mathrm{s}(\mathrm{W})$} \\
\hline Uninvolved quadriceps & $301(58)$ & $296(67)$ & 0.68 & 0.79 \\
\hline Involved quadriceps & $277(57)$ & $264(65)$ & 0.29 & 0.51 \\
\hline Uninvolved hamstrings & $179(42)$ & $172(37)$ & 0.43 & 0.50 \\
\hline Involved hamstrings & $173(41)$ & $154(32)$ & 0.03 & 0.07 \\
\hline \multicolumn{5}{|c|}{ Peak torque to body weight at $300 \% \mathrm{~s}(\%)$} \\
\hline Uninvolved quadriceps & $189(27)$ & $185(33)$ & 0.36 & 0.79 \\
\hline Involved quadriceps & $177(32)$ & $167(30)$ & 0.16 & 0.51 \\
\hline Uninvolved hamstrings & $134(23)$ & $126(23)$ & 0.12 & 0.45 \\
\hline Involved hamstrings & $128(24)$ & $118(17)$ & 0.04 & 0.07 \\
\hline \multicolumn{5}{|c|}{ Bilateral difference at $300 \% \mathrm{~s}(\%)$} \\
\hline Quadriceps & $-6(13)$ & $-9(12)$ & 0.32 & 0.48 \\
\hline Hamstrings & $-3(16)$ & $-5(14)$ & 0.67 & 0.67 \\
\hline \multicolumn{5}{|c|}{ Hamstring to quadriceps ratio at $300 \% \mathrm{~s}(\%)$} \\
\hline Involved leg & $74(12)$ & $73(15)$ & 0.75 & 0.75 \\
\hline Uninvolved leg & $71(11)$ & $70(15)$ & 0.50 & 0.50 \\
\hline \multicolumn{5}{|l|}{ Average power at $300 \% \mathrm{~s}(\mathrm{~W})$} \\
\hline Uninvolved quadriceps & $303(60)$ & $292(64)$ & 0.40 & 0.79 \\
\hline Involved quadriceps & $280(61)$ & $259(51)$ & 0.11 & 0.51 \\
\hline Uninvolved hamstrings & $173(43)$ & $172(48)$ & 0.97 & 0.97 \\
\hline Involved hamstrings & $171(47)$ & $148(30)$ & 0.02 & 0.07 \\
\hline \multicolumn{5}{|l|}{ Work fatigue at $300 \% \mathrm{~s}(\%)$} \\
\hline Uninvolved quadriceps & $34(9)$ & $34(15)$ & 0.79 & 0.79 \\
\hline Involved quadriceps & $32(12)$ & $32(9)$ & 0.98 & 0.98 \\
\hline Uninvolved hamstrings & $37(11)$ & $35(11)$ & 0.32 & 0.45 \\
\hline Involved hamstrings & $36(11)$ & $34(16)$ & 0.41 & 0.41 \\
\hline Average $\mathrm{t}$ test time $(\mathrm{s})$ & $10(1)$ & $10(1)$ & 0.92 & 0.92 \\
\hline Limb symmetry index (\%) & & & & \\
\hline Single hop & $97(6)$ & $99(5)$ & 0.16 & 0.48 \\
\hline Triple hop & $98(7)$ & $99(4)$ & 0.52 & 0.78 \\
\hline Crossover hop & $99(7)$ & $99(8)$ & 0.90 & 0.90 \\
\hline
\end{tabular}

Data are presented as mean (SD).

Bold type indicates statistical significance. 
body weight of the involved hamstrings at $300 \%$ s. These variables, as well as whether or not patients were fully discharged, were included in the Cox regression model.

The Cox regression model identified hamstring to quadriceps ratio at $60 \%$ and whether or not an athlete had been fully discharged as risk factors for an ACL graft rupture. Those who had a lower hamstring to quadriceps ratio had a greater risk of ACL graft rupture (HR 10.6 per $10 \%$ difference, $95 \%$ CI 10.2 to 11 , $\mathrm{p}=0.005)$, and those who were not fully discharged had a four times greater likelihood of sustaining an ACL graft rupture (HR 4.1, 95\% CI 1.9 to $9.2, \mathrm{p}<0.001)$.

\section{DISCUSSION}

We found that the athletes who did not meet the specific discharge criteria before RTS and were not fully discharged from ACLR rehabilitation by the surgeon had a four times greater risk of sustaining an ACL graft rupture (73\%) compared with those who returned to their sport after passing the RTS criteria $(27 \%)$.

Graft rupture rates ranging from $6 \%$ to $25 \%$ have been reported in the literature. ${ }^{1} 8{ }^{8} \quad{ }^{28-36}$ Bourke et $a l^{31}$ followed 186 patients for 15 years after isolated hamstring graft ACLR surgery and reported an $18 \%$ rate of ipsilateral ACL graft rupture for all age groups (average age 25.8 years). In a 2-year follow-up study of 98 patients who underwent ACLR, Kamien et $\mathrm{al}^{34}$ reported a $25 \%$ rate of graft failure for patients younger than 25 years. Therefore, the observed overall graft rupture rate of $17 \%$ observed in our study is comparable to previous literature, ${ }^{31} 34$ when taking into account the fact that every patient included in our study was a professional athlete of average age 22 years who went back to his pre-injury level of sports participation.

\section{Factors that might influence the risk of graft rupture}

One factor that is often considered to contribute to an increased risk of ACL graft rupture is premature RTS without following and meeting specific criteria. In our study, $70 \%$ of the ACL graft ruptures occurred during the first 6 months after RTS, which extends previous findings to the Gulf Region population. ${ }^{32} 37$

One explanation for the increased risk of ACL graft ruptures among athletes in our study who did not pass the discharge criteria could be impaired neuromuscular function. In a previous study, ${ }^{38}$ people with ACL injury who did not pass their RTS criteria had larger kinematic and kinetic asymmetries between limbs and used a gait strategy similar to athletes early after ACL rupture. The RTS tests and criteria we applied rigorously related to the known measures of biomechanical impairments. This suggests that neuromuscular asymmetries during dynamic movement may not only affect sport performance (and therefore lead to failing the RTS criteria), but may also predict the risk of a graft rupture.

We also identified a low hamstring to quadriceps strength ratio as a risk factor for ACL graft rupture. Strength, particularly quadriceps strength, has always been considered an important aspect of ACL rehabilitation and has been identified as a prerequisite for a successful outcome. ${ }^{39}$ Hamstring to quadriceps strength imbalances have also been suggested as a possible risk factor for ACL injuries, ${ }^{40} 41$ although there is limited direct evidence to support this. The hamstring muscles act as agonists to the ACL by resisting the anterior tibial displacement that results from quadriceps muscle forces at the knee. For this reason, the hamstring strength and the ratio of hamstring muscle strength to quadriceps muscle strength is often discussed as a risk factor for primary ACL rupture. ${ }^{2} 42$ Our results provide tantalising data suggesting this phenomenon may also be at play in the reconstructed ACL.

\section{Criteria for RTS}

Time to RTS (a surrogate measure of the strength and maturation of the ACL graft) is considered an important factor in RTS decision-making. The current clinical dogma is that RTS should not be permitted within 6 months of reconstruction. ${ }^{43} 44$ Although there is little evidence to substantiate this, Grindem and colleagues ${ }^{45}$ recently reported a $50 \%$ reduction in risk of knee re-injuries (all injuries, not only ACL) for each month that RTS is delayed beyond 6 months. However, in addition to time as a criterion, knee function evaluated by RTS tests is also a key element in the decision-making process. ${ }^{1}$

Several batteries of tests and discharge criteria are described for RTS. ${ }^{1} 31$ 46-50 These tests assess both function and strength. The maximum bilateral deficit recommended as acceptable for RTS clearance for functional and strength tests is between $10 \%$ and $15 \% .^{5152}$ The RTS criteria of our study were also in line with studies suggesting that a limb symmetry index of $90 \%$ in all hop tests and $85 \%$ in isokinetic strength tests be used. ${ }^{53}{ }^{54}$ It has been hypothesised that meeting these criteria implies a good recovery of muscle strength and neuromuscular control, and therefore ensures safe RTS.

The test batteries used to guide RTS are reliable and able to discriminate between people with ACL injury and healthy controls. ${ }^{53}$ However, no previous prospective studies have examined whether these RTS criteria predict those who are at increased risk of ACL graft rupture. Given the high incidence of ACL graft ruptures, there is legitimate concern over the clinical criteria that are used to determine clearance to RTS.

In our study, completing the rehabilitation programme and meeting our discharge criteria was associated with substantially lower odds of suffering an ACL graft rupture. Meeting stringent RTS criteria may reduce the risk of a future ACL graft rupture, and suggests that a RTS test battery with associated criteria may be a useful component of the RTS decision-making process. However, only $41 \%$ of surgeons report using strength or functional tests to assist their RTS decision-making. ${ }^{55}$

Although our multiple regression analysis did not identify hamstring weakness alone as a risk factor for graft rupture, the univariate tests showed a consistent trend of a hamstring strength deficit being associated with increased risk across all of the six strength variables tested $(p=0.04-0.08)$. We acknowledge that the current study was exploratory, not hypothesisdriven, and a large number of candidate risk factor variables were explored in the univariate analyses. As indicated by the adjusted $\mathrm{p}$ values, these findings must therefore be interpreted with caution. Nevertheless, these data suggest that sufficient hamstring strength and, consequently, an appropriate balance between hamstrings and quadriceps muscle strength is an important goal of ACL rehabilitation and should be used as a RTS criterion. However, these results need to be confirmed in future studies.

Our strength results cannot be compared with previous research since no studies have examined strength as a risk factor for ACL graft rupture. However, some research is available on strength as a risk factor for primary ACL injury. $^{40} 415657$ These studies confirm the importance of a balanced hamstring and quadriceps strength in people with ACL injury and are consistent with our findings. Raschner et $a l,{ }^{57}$ after retrospectively following 370 alpine skiers, concluded that hamstring to quadriceps ratio was significantly higher among athletes who did not sustain an ACL injury. 
Uhorchak et al, ${ }^{56}$ after a 4-year follow up of 895 USA military academy cadets, were not able to identify any of the strength ratios or parameters as a possible risk factor for an ACL injury. Although there were no significant differences in hamstring to quadriceps strength ratios, they reported a relatively higher risk of non-contact ACL injury for men who displayed greater eccentric quadriceps strength.

\section{Limitations and strengths of the study}

Our study has some limitations. First, the cohort examined comprised professional male athletes, mainly ethnic Arabs, which limits extrapolation to different populations. Second, the number of subjects included in this study was limited $(\mathrm{N}=158)$ and the number of ACL re-injured athletes was also small $(n=26)$. Third, limited variables were tested (strength and functional tests) and no movement analysis or neuromuscular assessment was performed. Follow-up was a minimum of 6 months for those who did not have an ACL graft rupture. Nevertheless, the mean follow-up was 786 days and, since the graft rupture rate is highest in the first 12 months (71\% of athletes included had passed this mark), we would argue that this justifies the approach taken. Whether the personality of individuals who do not complete their rehabilitation but RTS is associated with a greater risk of ACL graft rupture is something about which we are not in a position to comment.

A significant strength of this study is the tightly controlled and standardised discharge tests and criteria. All clinical staff associated with ACLR rehabilitation worked using a standardised discharge procedure. This approach minimised the variability of outcome associated with individual variations in rehabilitation. In addition, the study setting ensured that we registered all ACL graft ruptures.

\section{CONCLUSION}

Patients who did not meet the discharge criteria before returning to professional sport had a four times greater risk of sustaining an ACL graft rupture than those who passed the RTS criteria. In addition, hamstring strength deficits were associated with an increased risk of a graft tear.

\section{What are the findings?}

- Meeting six specific objective discharge criteria before return to sport after ACL reconstruction rehabilitation was associated with approximately one-quarter the risk of $\mathrm{ACL}$ graft rupture.

- For every $10 \%$ decrease in the hamstring to quadriceps strength ratio there was a 10.6 times higher risk of sustaining an $\mathrm{ACL}$ graft rupture.

\section{How might it impact on clinical practice in the future?}

- Meeting specific objective discharge criteria can reduce the relative risk of sustaining an $A C L$ graft rupture by four times.

- Careful attention to athletes achieving an appropriate hamstring to quadriceps strength ratio before discharge after $\mathrm{ACL}$ reconstruction may help to reduce the likelihood of $\mathrm{ACL}$ graft rupture.
Acknowledgements The authors warmly thank the medical records department of Aspetar Hospital for all their assistance.

Contributors PK conceived the study, collected the data, made the statistical analysis and wrote the manuscript. RB gave input with his research expertise as well as contributing to the study design and manuscript review. PL shared his surgical expertise. RM supported the effort to complete this study. EW supervised the study and contributed to the study design and manuscript review. All authors approved the final manuscript.

Competing interests None declared.

Ethics approval The study was approved by the Ethics Committee of the Anti-Doping Lab Qatar Institutional Review Board (IRB application number EX2013000006).

Provenance and peer review Not commissioned; externally peer reviewed.

\section{REFERENCES}

1 Barber-Westin SD, Noyes FR. Factors used to determine return to unrestricted sports activities after anterior cruciate ligament reconstruction. Arthroscopy 2011;27:1697-705.

2 Petersen $W$, Taheri P, Forkel $P$, et al. Return to play following ACL reconstruction: a systematic review about strength deficits. Arch Orthop Trauma Surg 2014; 134:1417-28.

3 Harris JD, Abrams GD, Bach BR, et al. Return to sport after ACL reconstruction. Orthopedics 2014;37:e103-8.

4 Rudolph K, Axe M, Snyder-Mackler L. Dynamic stability after ACL injury: who can hop? Knee Surg Sports Traumatol Arthrosc 2000;8:262-9.

5 Ardern CL, Taylor NF, Feller JA, et al. Fifty-five per cent return to competitive sport following anterior cruciate ligament reconstruction surgery: an updated systematic review and meta-analysis including aspects of physical functioning and contextual factors. Br J Sports Med 2014;48:1543-52.

6 Salmon L, Russell V, Musgrove T, et al. Incidence and risk factors for graft rupture and contralateral rupture after anterior cruciate ligament reconstruction. Arthroscopy 2005;21:948-57.

7 Soligard T, Nilstad A, Steffen K, et al. Compliance with a comprehensive warm-up programme to prevent injuries in youth football. Br J Sports Med 2010;44:787-93.

8 Pinczewski LA, Lyman J, Salmon LJ, et al. A 10-year comparison of anterior cruciate ligament reconstructions with hamstring tendon and patellar tendon autograft: a controlled, prospective trial. Am J Sports Med 2007;35:564-74.

9 Myklebust G, Holm I, Mæhlum S, et al. Clinical, functional, and radiologic outcome in team handball players 6 to 11 years after anterior cruciate ligament injury a follow-up study. Am J Sports Med 2003;31:981-9.

10 Waldén $M$, Hägglund $M$, Ekstrand J. High risk of new knee injury in elite footballers with previous anterior cruciate ligament injury. Br J Sports Med 2006;40:158-62.

11 Wright RW, Dunn WR, Amendola A, et al. Risk of tearing the intact anterior cruciate ligament in the contralateral knee and rupturing the anterior cruciate ligament graft during the first 2 years after anterior cruciate ligament reconstruction: a prospective MOON cohort study. Am J Sports Med 2007;35:1131-4.

12 Hui C, Salmon UJ, Kok A, et al. Fifteen-year outcome of endoscopic anterior cruciate ligament reconstruction with patellar tendon autograft for 'isolated' anterior cruciate ligament tear. Am J Sports Med 2011;39:89-98.

13 Wiggins AJ, Grandhi RK, Schneider DK, et al. Risk of secondary injury in younger athletes after anterior cruciate ligament reconstruction: a systematic review and meta-analysis. Am J Sports Med. Published Online First: 15 Jan 2016.

14 Paterno MV, Schmitt LC, Ford KR, et al. Biomechanical measures during landing and postural stability predict second anterior cruciate ligament injury after anterior cruciate ligament reconstruction and return to sport. Am J Sports Med 2010;38:1968-78.

15 Kaeding CC, Aros B, Pedroza A, et al. Allograft versus autograft anterior cruciate ligament reconstruction: predictors of failure from a MOON prospective longitudinal cohort. Sports Health 2011;3:73-81.

16 Shelbourne KD, Gray T, Haro M. Incidence of subsequent injury to either knee within 5 years after anterior cruciate ligament reconstruction with patellar tendon autograft. Am J Sports Med 2009;37:246-51.

17 Andernord D, Desai N, Björnsson $\mathrm{H}$, et al. Patient predictors of early revision surgery after anterior cruciate ligament reconstruction a cohort study of 16,930 patients with 2-year follow-up. Am J Sports Med 2014;43:121-7.

18 Eitzen I, Holm I, Risberg MA. Preoperative quadriceps strength is a significant predictor of knee function two years after anterior cruciate ligament reconstruction. Br J Sports Med 2009;43:371-6.

19 Paterno MV, Ford KR, Myer GD, et al. Limb asymmetries in landing and jumping 2 years following anterior cruciate ligament reconstruction. Clin J Sport Med 2007; 17:258-62.

20 Myer GD, Schmitt LC, Brent JL, et al. Utilization of modified NFL combine testing to identify functional deficits in athletes following $\mathrm{ACL}$ reconstruction. J Orthop Sports Phys Ther 2011:41:377. 
21 Kyritsis P, Witvrouw E, Landreau P. Return to the field for football (Soccer) after anterior cruciate ligament reconstruction: guidelines. Sports Inj Prev Diagn Treat Rehabil 2015;4:1503-15.

22 Munro AG, Herrington LC. Between-session reliability of four hop tests and the agility T test. J Strength Cond Res 2011;25:1470-7.

23 Pauole K, Madole K, Garhammer J, et al. Reliability and validity of the T test as a measure of agility, leg power, and leg speed in college-aged men and women. J Strength Cond Res 2000;14:443-50.

24 Hopper DM, Goh SC, Wentworth LA, et al. Test-retest reliability of knee rating scales and functional hop tests one year following anterior cruciate ligament reconstruction. Phys Ther Sport 2002;3:10-18.

25 Reid A, Birmingham TB, Stratford PW, et al. Hop testing provides a reliable and valid outcome measure during rehabilitation after anterior cruciate ligament reconstruction. Phys Ther 2007;87:337-49.

26 Ross MD, Langford B, WHELAN PJ. Test-retest reliability of 4 single-leg horizontal hop tests. J Strength Cond Res 2002;16:617-22.

27 Benjamini Y, Hochberg Y. Controlling the false discovery rate: a practical and powerful approach to multiple testing. J R Stat Soc Ser B Methodol 1995:289-300.

28 Keays SL, Bullock-Saxton JE, Keays AC, et al. A 6-year follow-up of the effect of graft site on strength, stability, range of motion, function, and joint degeneration after anterior cruciate ligament reconstruction: patellar tendon versus semitendinosus and gracilis tendon graft. Am J Sports Med 2007;35:729-39.

29 Ahldén M, Samuelsson K, Sernert N, et al. The Swedish national anterior cruciate ligament register: a report on baseline variables and outcomes of surgery for almost 18,000 patients. Am J Sports Med 2012;40:2230-5.

30 Ellis HB, Matheny LM, Briggs KK, et al. Outcomes and revision rate after bonepatellar tendon-bone allograft versus autograft anterior cruciate ligament reconstruction in patients aged 18 years or younger with closed physes. Arthroscopy 2012;28:1819-25.

31 Bourke HE, Gordon DJ, Salmon LJ, et al. The outcome at 15 years of endoscopic anterior cruciate ligament reconstruction using hamstring tendon autograft for 'isolated' anterior cruciate ligament rupture. J Bone Joint Surg Br 2012;94:630-7.

32 Webster KE, Feller JA, Leigh WB, et al. Younger patients are at increased risk for graft rupture and contralateral injury after anterior cruciate ligament reconstruction. Am J Sports Med 2014;42:641-7.

33 Magnussen RA, Lawrence JTR, West RL, et al. Graft size and patient age are predictors of early revision after anterior cruciate ligament reconstruction with hamstring autograft. Arthroscopy 2012;28:526-31.

34 Kamien PM, Hydrick JM, Replogle WH, et al. Age, graft size, and Tegner activity level as predictors of failure in anterior cruciate ligament reconstruction with hamstring autograft. Am J Sports Med 2013;41:1808-12.

35 Kamath GV, Murphy T, Creighton RA, et al. Anterior cruciate ligament injury, return to play, and reinjury in the elite collegiate athlete: analysis of an NCAA Division I cohort. Am J Sports Med 2014;42:1638-43.

36 Laboute E, Savalli L, Puig P, et al. Analysis of return to competition and repeat rupture for 298 anterior cruciate ligament reconstructions with patellar or hamstring tendon autograft in sportspeople. Ann Phys Rehabil Med 2010;53:598-614.

37 Schlumberger $M$, Schuster $P$, Schulz $M$, et al. Traumatic graft rupture after primary and revision anterior cruciate ligament reconstruction: retrospective analysis of incidence and risk factors in 2915 cases. Knee Surg Sports Traumatol Arthrosc. Published Online First: 26 Sep 2015.

38 Di Stasi SL, Snyder-Mackler L. The effects of neuromuscular training on the gait patterns of ACL-deficient men and women. Clin Biomech 2012;27:360-5.
39 Snyder-Mackler L, Delitto A, Bailey S, et al. Strength of the quadriceps femoris muscle and functional recovery after reconstruction of the anterior cruciate ligament. J Bone Joint Surg Am 1995;77:1166-73.

40 Knapik JJ, Bauman CL, Jones BH, et al. Preseason strength and flexibility imbalances associated with athletic injuries in female collegiate athletes. Am J Sports Med 1991;19:76-81.

41 Söderman K, Alfredson H, Pietilä T, et al. Risk factors for leg injuries in female soccer players: a prospective investigation during one out-door season. Knee Surg Sports Traumatol Arthrosc 2001;9:313-21.

42 Aagaard P, Simonsen EB, Magnusson SP, et al. A new concept for isokinetic hamstring: quadriceps muscle strength ratio. Am J Sports Med 1998;26:231-7.

43 MacDonald PB, Hedden D, Pacin O, et al. Effects of an accelerated rehabilitation program after anterior cruciate ligament reconstruction with combined semitendinosus-gracilis autograft and a ligament augmentation device. Am J Sports Med 1995;23:588-92.

44 Shelbourne KD, Nitz P. Accelerated rehabilitation after anterior cruciate ligament reconstruction. Am J Sports Med 1990;18:292-9.

45 Grindem H, Snyder-Mackler L, Moksnes H, et al. Simple decision rules reduce reinjury risk after anterior cruciate ligament reconstruction: the Delaware-Oslo cohort study. Br J Sports Med Published Online First: 9 May 2016 doi:10.1136/ bjsports-2016-096031

46 Clover J, Wall J. Return-to-play criteria following sports injury. Clin Sports Med 2010;29:169-75.

47 Creighton DW, Shrier I, Shultz R, et al. Return-to-play in sport: a decision-based model. Clin J Sport Med 2010;20:379-85.

48 Dauty M, Le Brun J, Huguet $\mathrm{D}$, et al. [Return to pivot-contact sports after anterior cruciate ligament reconstruction: patellar tendon or hamstring autografts]. Rev Chir Orthop Reparatrice Appar Mot 2008;94:552-60.

49 Grindem H, Logerstedt D, Eitzen I, et al. Single-legged hop tests as predictors of self-reported knee function in nonoperatively treated individuals with anterior cruciate ligament injury. Am J Sports Med 2011;39:2347-54.

50 Paterno MV, Rauh MJ, Schmitt LC, et al. Incidence of second ACL injuries 2 years after primary $\mathrm{ACL}$ reconstruction and return to sport. Am J Sports Med 2014;42:1567-73.

51 Sapega A. Muscle performance evaluation in orthopaedic practice. J Bone Joint Surg 1990;72:1562-74.

52 Augestad L, Tøndel S. Isokinetic muscle strength after anterior cruciate ligament reconstruction. Scand J Med Sci Sports 1998;8:279-82.

53 Gustavsson A, Neeter $C$, Thomeé $P$, et al. A test battery for evaluating hop performance in patients with an $A C L$ injury and patients who have undergone $A C L$ reconstruction. Knee Surg Sports Traumatol Arthrosc 2006;14:778-88.

54 Neeter C, Gustavsson A, Thomeé P, et al. Development of a strength test battery fo evaluating leg muscle power after anterior cruciate ligament injury and reconstruction. Knee Surg Sports Traumatol Arthrosc 2006;14:571-80.

55 Petersen W, Zantop T. Return to play following $\mathrm{ACL}$ reconstruction: survey among experienced arthroscopic surgeons (AGA instructors). Arch Orthop Trauma Surg 2013;133:969-77.

56 Uhorchak JM, Scoville CR, Williams GN, et al. Risk factors associated with noncontact injury of the anterior cruciate ligament a prospective four-year evaluation of 859 west point cadets. Am J Sports Med 2003;31:831-42.

57 Raschner C, Platzer H-P, Patterson C, et al. The relationship between ACL injuries and physical fitness in young competitive ski racers: a 10-year longitudinal study. Br J Sports Med 2012;46:1065-71. 